\title{
Ecological awareness of university students about UN sustainable development goals at global, national and regional levels
}

\author{
O. M. Kazakova ${ }^{1 *}$, T. N. Malinovskaia ${ }^{2}$, B. A. Fedulov ${ }^{2}$, E. V. Romanova ${ }^{1}$ \\ A. G. Zavgorodnii ${ }^{2}$, N. S. Matveychuk ${ }^{2}$ \\ ${ }^{1}$ Altai State University, Barnaul, Russia. \\ https://orcid.org/0000-0003-4317-605X \\ ${ }^{2}$ Barnaul Law Institute of the Ministry of Internal Affairs of Russia, Barnaul, Russia. \\ E-mail: kazakova-olga@mail.ru
}

Received: 06.02.2020 Accepted 06.03.2020

\begin{abstract}
The article presents a research of the ecological awareness of young people studying at universities. The research was carried out in the framework of global issues, including environmental, presented as goals in the United Nations program of 17 Sustainable Development Goals. The UN SDGs is a comprehensive global framework for the better future of the planet and its people aimed at solving urgent problems in the world and adopted by global community. The authors conducted a sociological survey of university students living mostly in the South-West of Siberia about their knowledge of the Sustainable Development Goals and understanding of global problems that humanity is facing. They questioned the respondents about their opinion on the priority of global issues what problems must be solved first of all: environmental, social or economic. The problems in the questionnaire were presented in the wording of the UN Sustainable Development Goals. The respondents have chosen the most urgent problems at global, national and regional levels. Their priorities were not the same at different levels. At the same time the research have shown that many university students in the surveyed region do not know about the United Nations program of 17 Sustainable Development Goals, which began in 2015 and has been in progress already for four years. To study young people's attitude to solving global problems, the university students were asked if they can help and what they can personally do in that respect. The survey revealed active position of many students toward ecological and other problems. The results of the research were analyzed and presented in the form of seven tables.
\end{abstract}

Key words: Ecology; Environment; Environmental problems; Sustainable development; United Nations SDGs; University students

\section{Introduction}

In 2015 the United Nations adopted a global program of achieving 17 Sustainable Development Goals (SDGs) by 2030 - the blueprint for a better and more sustainable future for all, a global framework to solve environmental, social and economic problems. They address such global challenges as environmental degradation, poverty, inequality, climate change, and peace and justice. Environmental problems take half of the goals: Goal 6 -Clean water and sanitation; Goal 7 - Affordable and clean energy; Goal 11 Sustainable cities and communities; Goal 12 - Responsible consumption and production; Goal 13 - Climate action; Goal 14 - Life below water; Goal 15 - Life on land. To implement the SDGs, it is necessary to create corresponding programs at national and regional levels involving all social institutions - governments, business, universities and local communities. The role of universities in that process is essential; they are to become centers of information and cooperation in solving global environmental problems and implementing the Goals. By teaching the students to understand the current environmental issues and motivating them to take an active attitude towards those problems, we can bring up a generation of environmental awareness and responsibility. The authors decided to conduct a sociological survey to understand the current state of students' minds, their awareness of global problems including environmental, knowledge about the global practices and the United Nations program of 17 Sustainable Development Goals. The purpose of the study was to find out what university students know about environmental problems and the state of ecology at global, country and regional levels, if they are informed about the United Nations Sustainable Development Goals on environment, and what is their attitude to the solution of those problems. The authors studied students' opinions and intentions at regional level attracting respondents mostly from one particular region.

\section{Methods}

The research started with setting the goal through empirical method of observation which was used in pedagogical process with university students. The authors have been discussing global issues with undergraduate and postgraduate students for about two decades (Kazakova, 2017; Romanova, 2016) and were able to observe changes in their attitude to solving ecological, social, health, and other problems of humanity. Observations led to more objective quantitative method. To study the students' knowledge about global efforts in the sphere of solving environmental problems and their attitude (active or passive) towards ecology, the authors 
used an empirical method of sociological survey. A questionnaire of 12 questions was made and then answered by 448 university students. The results of the survey were analyzed and presented in the form of tables.

\section{Results}

The authors conducted a survey to understand how well university students in their region understand ecological and other global problems and if they are informed about the UN SDGs.

An anonymous questionnaire was completed by 448 students in several universities but mostly in the Russian Federation. The majority of the respondents (94\%) were from Russia, $1 \%$ from Kazakhstan, and the rest were equally divided among USA and Tajikistan. Gender distribution of the respondents: female $-74 \% \%$, male $-26 \%$.

Regional distribution of the respondents: the majority (83\%) from the South-Western Siberia: the Altai Territory (prevailing majority $-81 \%)$, the Republic of Altai and the Novosibirsk Region.

The 1st question of the questionnaire was "What important problems for humanity should be solved in the first place: economic, political, social, cultural, environmental, psychological, or other (specify)?" The most common answer (46,2\%) was "environmentalproblems" with social and economic problems coming as second important (17\% and 15\% correspondingly). That and other results are shown in Table 1.

Table 1. What important problems for humanity should be solved in the first place.

\begin{tabular}{lc}
\hline $\begin{array}{l}\text { What important problems for humanity should be } \\
\text { solved in the first place? }\end{array}$ & Results, \% \\
Environmental & 46,2 \\
Social & 17 \\
Economic & 15 \\
Psychological & 8 \\
Political & 8 \\
Cultural & 4 \\
All problems must be solved & 0,6 \\
The problem is in people. Without certain measures and & 0,2 \\
willingness of humanity there'll be no better culture, or & \\
ecology & \\
\hline
\end{tabular}

Thus, the students showed understanding of the urgency of solving ecological problems. They also feel that the environment is closely interconnected with society and economics, so they have chosen the corresponding problems being of next importance. Interestingly, the notion of sustainable development includes the triangle of economic development, social inclusion and environmental sustainability; it is the basic idea for the United Nations' program of 17 SDGs that include three main Ps - prosperity, people and planet (Sachs, 2014). The survey results show that the UN program reflects deep concerns of young people about ecology. The $2^{\text {nd }}$ questionnaire question, "Have you heard about the UN Sustainable Development Goals", was to find out if the students know about the UN SDGs. Only about a third (36\%) of respondents answered positively to that question. The majority of university students don't know anything about UN SDGs.

It's a worrying sign as universities are responsible for achieving the Sustainable Development Goals as centers of education, scientific research and innovations. They are to help solve environmental, economic and social problems of the community as well as global ones.

Next three questions of the questionnaire were about the priority of world problems at different levels: global, national and regional. The respondents could choose several goals. The multiple choice variants were created with the use of UN SDGs. The results are presented in Tables 2, 3 and 4 in descending order of importance.

Table 2. Specify, what global goals of mankind it is necessary to solve first of all.

\begin{tabular}{ll}
\hline Specify, what global goals of mankind it is necessary to solve first of all? & Results, \% \\
Eliminate poverty and hunger on the planet & 48 \\
Protecting, restoring and promoting sustainable use of terrestrial ecosystem, & 43 \\
managing forests, combating desertification, halting and reversing land degradation & \\
and halting biodiversity loss & 28 \\
Combating climate change and its consequences & 27 \\
Transition to rational models of consumption and production & 23 \\
Clean water and sanitation & 23 \\
Create conditions for quality education & 23 \\
Achieve gender equality and reduce inequality in the world as a whole & 22 \\
Conservation and sustainable use of oceans, seas and marine resources for & 22 \\
sustainable development & 17 \\
Improve human health & 16 \\
Justice and effective institutions & 16 \\
Decent work and economic growth & \\
Transition to low-cost and clean energy & \\
\hline
\end{tabular}

The results from Tables 2, 3 and 4 provide information about respondents' attitude to the same goals but at different perspectives. 
Table 3. What are the priority problems in your state.

\section{What are the priority problems in your state?}

Eliminate poverty and hunger on the planet

Decent work and economic growth

\section{Results, \%}

20

14

Create conditions for quality education. Achieve gender equality and reduce 13 inequality in the world as a whole

Justice and effective institutions

Protecting, restoring and promoting sustainable use of terrestrial ecosystems, 11 managing forests, combating desertification, halting and reversing land degradation and halting biodiversity loss

Improve human health

Transition to rational models of consumption and production. Transition to low- 6 cost and clean energy

Achieve gender equality and reduce inequality in the world as a whole

Combating climate change and its consequences Transition to rational models 3

of consumption and production

Transition to low-cost and clean energy

Conservation and sustainable use of oceans, seas and marine resources for 2 sustainable development

Building sustainable cities

Clean water and sanitation 1

Seen globally and nation-wide, the most urgent problem for the students is "Eliminate poverty and hunger on the planet", it is also of second importance at regional level.

Table 4. What are the priority problems in your region.

\section{What are the priority problems in your region?}

Decent work and economic growth

Eliminate poverty and hunger on the planet

Create conditions for quality education

Achieve gender equality and reduce inequality in the world as a whole

Improve human health

Results, \%
29
15
10
10
9

\section{Results, \%}

Protecting, restoring and promoting sustainable use of terrestrial ecosystems, 9 managing forests, combating desertification, halting and reversing land degradation and halting biodiversity loss

Transition to rational models of consumption and production. Transition to low- 6 cost and clean energy

Clean water and sanitation

Combating climate change and its consequences

Justice and effective institutions

Achieve gender equality and reduce inequality in the world as a whole

Building sustainable cities

Transition to low-cost and clean energy

Conservation and sustainable use of oceans, seas and marine resources for 1

sustainable development

The most important regional problem is "Decent work and economic growth", which is almost twice as important compared with poverty and hunger reduction ( $29 \%$ and $15 \%$ ). Environmental problems take the second place only at global level, but at national and regional levels they are less important for respondents, giving place to economic and social problems, the tendency being especially strong regionally. Students understand the necessity to solve ecological problems globally but when asked about their country or region, answer that they need a good job and decent pay as well as better education. It is quite natural for a landlocked region of Altai to give priority to protecting life on land and not to pay attention to sustainable use of oceans, seas and marine resources. Human health goal comes in the middle of the ratings. Questions 6, 7 and 8 of the questionnaire were devoted to personal attitude (active or passive) of respondents to solving global issues. The results are shown in Tables 5, 6 and 7. Table 5 shows more active attitude of the respondents towards the environment than passive. Only $15 \%$ answered that they cannot do anything to solve those problems. $34 \%$ of students think that it depends on them but not much. One third of the respondents take an active position and are ready to take care of the environment. $12 \%$ even feel personal responsibility for solving global problems. The remained $6 \%$ are ready to share information with others. 
Table 5. In your opinion, does anything depend on you in solving these problems.

\begin{tabular}{lc}
\hline In your opinion, does anything depend on you in solving these Results, \% \\
problems? \\
No, it doesn't \\
Yes, it does, but to a small extent & 15 \\
Yes, it does, I can talk about it to others & 34 \\
Yes, I can take care of the environment & 6 \\
Yes, I feel personally responsible for solving problems in the world & 33 \\
\hline
\end{tabular}

Table 6. How much do you think you can help solve the global problems of humanity.

\begin{tabular}{ll}
\hline How much do you think you can help solve the global problems of Results, $\%$ \\
humanity? \\
Not at all & 9 \\
To a small extent & 71 \\
I can make a significant contribution to solving these problems & 20 \\
\hline
\end{tabular}

In Table 6 most respondents (71\%) are ready to help solve global problems but to a small extent. $20 \%$ show active stance. $9 \%$ don't think they can help in this respect.

Table 7. What can you do to solve these problems.

\begin{tabular}{ll}
\hline What can you do to solve these problems? & Results, \% \\
I can tell people around me about it & 21 \\
I can change my attitude and lifestyle to solve global problems & 54 \\
I can hold events and involve other people in solving these problems & 19 \\
I can't do anything & 6 \\
\hline
\end{tabular}

Table 7 shows the students' readiness to solve ecological and other problems of the planet. Only $6 \%$ replied that they couldn't do anything. More than a half (54\%) are ready to change their attitude and lifestyle. $21 \%$ want to share information. $19 \%$ of respondents are even ready to organize environmental events and involve others. Summing up the results of Tables 5, 6 and 7, it can be observed that the university students take quite an active attitude towards solving environmental and other global issues, with small percentage of completely inactive respondents. Though the degree of activity varies from small readiness to participate and change to involvement in more active actions, the general tendency is that young people want to participate in solving global problems.

\section{Discussion}

The survey of university students from Altai has shown that young people of the region are concerned about ecological problems, especially at global level. At national and regional levels they are more concerned about economic and social problems. Thus, additional efforts and comprehensive programs are needed to form ecological awareness of young generation. They should receive information about environmental sustainability and sustainable development that comprises economic, social and environmental aspects. The process of ecological education must begin in school and continue in university. Young people must be explained that economic development without considering environmental and social aspects can lead the humanity to a disaster. The idea of sustainable development must become a standard practice and be implemented at national and regional levels.

It would be of scientific interest to conduct a similar survey for schoolchildren with the purpose of comparing different age groups' attitude to ecological and other global issues. It may be also useful to survey students from other regions within Russia and other countries. A lot has to be done to inform young people about the United Nations Sustainable Development Goals, as only $36 \%$ of the surveyed have heard about them. The authors believe that universities must take more active part in educating people about SDGs and implementing them at regional level. It's a worrying sign that university students - future specialists, a social group that is receiving higher education - know so little in that respect. The responsibility for that is on educational system, first of all, but each individual, university professors or proactive student communities can make a difference as well.

\section{Conclusion}

The research of ecological awareness of young people in universities has revealed the state of students' environmental knowledge and their position concerning the solution of ecological and other pressing problems of humanity. They are aware of the environmental crisis at global scale but tend to give priority to economic and social issues at nation-wide and regional levels. It is quite natural for young people who want to find a well-paid job and gain a social role of importance. Global problems, environmental degradation, climate change seem important but far-away issues for the students from the South-Western Siberia. They need more information, timely education since school years to realize that ecology begins at home, starting with daily habits and lifestyle and ending with environmental activism and feeling of personal responsibility for solving problems in the world. And the youth is ready to act, the majority of the surveyed answered that to a certain extent it depends on them to solve the global problems. One fifth of the respondents are even ready to make a significant contribution to solving these problems. More than a half can change their attitude and lifestyle. $21 \%$ can tell people around them. $19 \%$ can hold events and involve other people in solving these problems. Only $6 \%$ feel that they can't do anything. The data of the survey provides ground for optimism that the young generation will be able to make a difference and find new solutions for ecological problems. 


\section{References}

United Nations Sustainable Development Goals. Date of update: 11.03.2019.

Kazakova, O.M. (2017). Discussing Sustainable Development Goals with Students of International Relations. Language, Culture, Education, Issues of Modern Communication, Barnaul.

Sachs, J. D. (2015). The Age of Sustainable Development. Columbia University Press, New York.

Guryev, S.V. (2019). The problem of social methods of influence on the organization of the rational regime of work and rest of students. Health, Physical Culture and Sports, 1 (12), 65-78.

Romanova, E.V. (2016). Youth health in the study of addictive behaviors. Health, Physical Culture and Sports, 2. - pp.14-24.

Dugnist, P.Ya.,Milkhin, V.A., Golovin, S.M., Romanova, E.V. (2017). Healthy lifestyle in the system of value orientations of youth. Health, Physical Culture and Sports, 4 (7), 3-25.

Arpentieva, M. R. (2018). Health saving in a university: problems and prospects. Health, Physical Culture and Sports, 4 (11), 14-36. Savko, E.I., Hojempo, S.V. (2018). Students and their attitude to physical education, and a healthy lifestyle. Health, Physical Culture and Sports, 4 (11), 62-76.

\section{Citation:}

Kazakova, O.M., Malinovskaia, T.N., Fedulov, B.A., Romanova, E.V., Zavgorodnii, A.G., Matveychuk, N.S. (2020). Ecological awareness of university students about UN Sustainable Development Goals at global, national and regional levels. Ukrainian Journal of Ecology, 10(1), 215-219 . 